\title{
Does Hamulotomy Affects Hearing Range? A Prospective Clinical Study
}

\section{Pradeep Kumar Das ${ }^{1}$, Abhishek Kumar Singh ${ }^{2 *}$, Jingade krishnojirao dayashankara rao $^{3}$, Alok Bhatnagar ${ }^{4}$, Prachi Singh ${ }^{5}$ and Aparajita ${ }^{6}$}

${ }^{1}$ Consultant Oral and Maxillofacial Surgeon, Oral and Maxillofacial Surgery, India

${ }^{2}$ Senior Lecturer, Department of Oral and Maxillofacial Surgery, Buddha Institute

of Dental Sciences and Hospital, Patna, Bihar, India

${ }^{3}$ Associate Professor, College of Dentistry, Qassim University Buraida, Al Qassim

Region, Saudi Arabia

${ }^{4}$ Associate Professor, Department of Oral and Maxillofacial Surgery, S.G.T

University Gurugram, Haryana, India

${ }^{5}$ Consultant Periodontologist and Implantologist, Periodontology and

Implantology, India

${ }^{6}$ Consultant Oral Surgeon, Bachelor of Dental Sciences, India

*Corresponding Author: Abhishek Kumar Singh, Senior Lecturer, Department of Oral and Maxillofacial Surgery, Buddha Institute of Dental Sciences and Hospital,

Patna, Bihar, India.
Received: March 01, 2021

Published: April 09, 2021

(C) All rights are reserved by Abhishek Kumar Singh., et al.

\begin{abstract}
Objectives: To determine the actual need of hamulotomy during palatoplasty is beneficial or detrimental with respect to intraoperative and post-operative complications and also to assess the effect on hearing and the incidence of post-operative palatal fistula. Materials and Methods: 30 patients of cleft palate deformities requiring primary cleft palate repair were randomly divided into 2 groups; Group A, Palatoplasty with hamulotomy and Group B, Palatoplasty without hamulotomy. All patients were subjected to Otoscopic and Audiometric examinations; pre-operatively, $1^{\text {st }}$ month and $6^{\text {th }}$ month post-operatively.

Results: In Otoscopic examination, pre-operatively $73 \%$ had positive otological findings for hamulotomy group while in non hamulotomy group, $20 \%$ were chronically affected. On comparing these two groups, there were difference in the improvement of middle ear status in both the groups which was statistically significant $(\mathrm{p}<0.005)$. After 6 months post-operatively, Audiometric findings showed no statistically significant difference $(p>0.005)$ within both the groups and also when compared to each other, there was no statistically significant differences $(\mathrm{p}>0.005)$. Complication rates in both the groups was statistically not significant ( $p>0.005)$.

Conclusion: We concluded that the study seems, hamulotomy does not alter the hearing ability in cleft palate population. In wider clefts, successful closure can be done without hamulotomy and for repairing of narrow or, moderate clefts hamulotomy may not require.
\end{abstract}

Keywords: Hamulotomy; Hearing Range; Palatoplasty; Post-Operative Palatal Fistula

\section{Introduction}

In ancient times, it was believed that the birth defects are result of some action of supernatural forces and also viewed as exempli- fication of evil and sometimes as intimation of God's warnings for forthcoming disasters [1]. Development of the head and face condemn one of the most complicated events during embryonic devel- 
opment [1]. Craniofacial abnormalities like orofacial clefts, cleft lip and/or cleft palate are seen as most common and most frequent birth defects. Cleft lip and/or cleft palate results in complexity which out-turn into feeding, speech, hearing and psychological development [1]. Incidence of cleft lip or cleft palate is approximately 1 in 700 children and is more common in boys but isolated cleft palate is twice as common in girls [2]. In cleft palate, the muscles of the soft palate are hypoplastic and insert in the posterior margin of the remaining hard palate rather than the midline raphe [3]. Among the most important goals of reconstructing the cleft palate are the restoration of normal anatomic separation of the oral and nasal cavities, normal speech and maintenance of ear function. The incidences of middle ear effusion, otitis media, and hearing impairment are high in patients with cleft palate [9].

A successful repair of palatal cleft is carried out by preserving maximal tissue along good blood supply with a tension free closure of the defect. The narrow clefts can be closed easily without tension usually by any of the surgical techniques. On the other hand, closure of wider clefts may result in tension across the suture line with focal fistula formation. By avoiding fracture of pterygoid hamulus, there may be a failure of total release of the muscles which might cause tension on the suture line and can lead to form fistula. The occurrence of a fistula after palate repair clearly compromises resulting in nasal emission during speech and deglutition and represents a challenging problem for the cleft treatment team [10].

\section{Aim and Objectives}

1. To determine the actual need for fracturing the Pterygoid Hamulus in palatoplasty.

2. To determine whether, in performing palatoplasty, fracture of the pterygoid Hamulus is beneficial or, detrimental with respect to intra-operative and post-operative complications.

3. To assess the effect of hamulus process fracture on hearing and the incidence of post-operative palatal fistula.

\section{Materials and Methods}

30 patients of cleft palate deformities were admitted in the Department of Oral and Maxillofacial Surgery, Faculty of Dental Sciences, SGT University, Gurugram. All type of cleft patient was described according to the Veau's classification and all patients were operated by a single surgeon and were examined in a regular follow-up visits by same members of the cleft palate team and ENT surgeons. The patients were divided into two groups randomly by drawing chits:
- Group A: Cleft palate repair surgery done with pterygoid hamulus fracture (Figure 1).

- Group B: Cleft palate repair surgery done without pterygoid hamulus fracture (Figure 2).

\section{Inclusion criteria}

Primary cleft palate patient aged between 10 months to 5 years, both male and female, non-syndromic cases, medically fit to undergo surgical intervention (ASA Type I and II) and, who consented for follow up.

\section{Exclusion criteria}

Patients with previous history of, any ear surgery, ventilation tube insertion, grommet insertion or myringotomy, tympanic membrane perforation, chronic suppurative otitis media with effusion, cholesteatoma formation, retraction pockets, ossicular fixation, undergone any secondary procedure to improve the velopharyngeal mechanism, congenital hearing loss and congenital auricular malformations and medically compromised patient, (ASA Type III and IV). Patients with possible compromised immune status or systemic disease, craniofacial anomalies, associated syndromes, and delayed achievement of developmental milestones were not considered.

\section{Operative procedure}

Both the groups underwent Wardwill-kilner V Y Pushback palatoplasty under General Anaesthesia. Under standard general anesthesia protocol, patients were prepared and draped and anesthesia was induced; Dingman's mouth gag was secured. Depending on patient's weight, $2 \mathrm{ml}$ - 4ml 2\% lidocaine (Xylocaine) with 1:200,000 epinephrine solution was infiltrated to all the patients. The edges of the cleft were pared with a \#15 scalpel blade, starting from the anterior hard palate area towards the uvula. Only a thin rim of tissue was removed so that the nasal and buccal mucosa could be seen, with the muscle layer of the soft palate between them. The hamular process was usually easily palpable just medial and posterior to the maxillary tuberosity. Hamulotomy was performed for Group A patients. A small swab was then placed in this wound, while the hamulus was fractured on both the sides inward bilaterally, by pressure exerted with an elevator to release the TVP muscle from hamular notch converting tensor into levator. This maneuver was performed in a similar manner on each patient assigned to the fracture group, independent of the technique of palatoplasty (Figure 1). For the Group B patients, hamulotomy was avoided. Closure was done in two layers, i.e. oral layer and nasal layer, using absorbable 
Vicryl suture material. Both the layers were approximated at a few points to obliterate dead space (Figure 2). Postoperatively, the patients were closely monitored in the paediatric intensive care unit for 24 hours. Antibiotics and analgesic was given post-operatively.
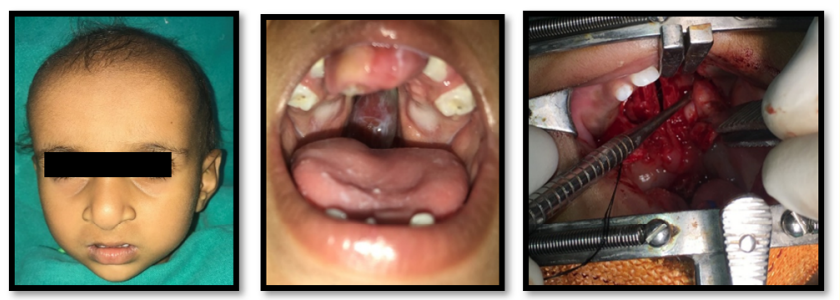

Figure 1: Group A. Extra oral intra oral hamulotomy performed.
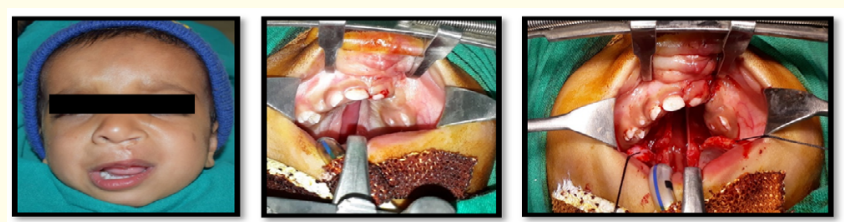

Figure 2: Group B. Extra oral intra oral hamulotomy avoided.

All the patients were subjected to Otoscopic and Audiometric examination. Otoscopic examination was done through otoscope (Table 1) and function Auditory evaluation was done by Brainstem Evoked Response Audiometry (BERA) (Table 2); preoperatively, 1 month and 6 months postoperatively by an experienced otolaryngologist of the cleft team, each patient were laid down and relaxed in an air-conditioned, sound attenuated chamber while sleeping naturally or very quietly awake. It was conducted under natural sleep as far as possible. For non-cooperative patients, syrup Pedicloryl, Dr. Reddy's (Triclofas Sodium IP $500 \mathrm{mg}, 0.5 \mathrm{ml} / \mathrm{kg}$ ) was used to induce sleep. Those patients in whom sedation was not given was instructed to close their eyes to avoid blink artifacts. Medicaid, was used to record the evoked potential from the scalp of the patients with silver chloride disc electrodes from standard scalp locations of 10 - 20 international systems. The standard electrode montage of left mastoid, right mastoid, forehead, and scalp was used after cleaning the scalp and skin with alcohol followed by RMS recording paste. The skin electrode contact impedance was maintained at $5 \mathrm{~K}$ ohms or less. For recording active electrode potential, 2000 click stimuli at the rate of $11.1 \mathrm{~Hz}$ with duration of $0.1 \mathrm{~ms}$ was delivered at $60 \mathrm{~dB}$ above hearing threshold through shield headphones with $-20 \mathrm{~dB}$ white noise masking the contralateral ear. Signals were filtered with band pass of $100 \mathrm{~Hz}$ and $3 \mathrm{KHz}$ and was averaged to 2000 stimuli. Absolute latencies of waves I and V, interpeak latencies of waves I-V, amplitude ratio of waves V-I, and latency intensity function was determined for each ear separately. Degree of hearing impairment was assessed and documented. These data served as a document of patient and was classified in to four different numbers: Normal, Mild, Moderate and Severe.

\begin{tabular}{|c|c|c|c|c|c|c|}
\hline \multicolumn{7}{|c|}{ Otoscopic findings } \\
\hline & \multicolumn{3}{|c|}{ Group A } & \multicolumn{3}{|c|}{ Group B } \\
\hline & Pre-op. & $1^{\text {st }}$ month & $6^{\text {th }}$ month & Pre-op. & $1^{\text {st }}$ month & $\begin{array}{c}6^{\text {th }} \\
\text { month }\end{array}$ \\
\hline Normal & 4 & 3 & 5 & 12 & 13 & 14 \\
\hline Dull & 0 & 0 & 0 & 1 & 1 & 1 \\
\hline Retracted & 9 & 10 & 8 & 2 & 1 & 0 \\
\hline Bulging & 2 & 2 & 2 & 0 & 0 & 0 \\
\hline
\end{tabular}

Table 1: All the numerical values are indicating number of patients.

\begin{tabular}{|l|c|c|c|c|c|c|}
\hline \multicolumn{7}{|c|}{ Audiometric Findings } \\
\hline & \multicolumn{3}{|c|}{ Group A } & \multicolumn{3}{c|}{ Group B } \\
\cline { 2 - 7 } & Pre-op. & $\begin{array}{c}1^{\text {st }} \\
\text { month }\end{array}$ & $\mathbf{6}^{\text {th }}$ month & Pre-op. & $\begin{array}{c}1^{\text {st }} \\
\text { month }\end{array}$ & $\begin{array}{c}\mathbf{6}^{\text {th }} \\
\text { month }\end{array}$ \\
\hline Normal & 10 & 13 & 13 & 14 & 15 & 15 \\
\hline Mild & 4 & 2 & 2 & 1 & 0 & 0 \\
\hline Moderate & 1 & 0 & 0 & 0 & 0 & 0 \\
\hline Severe & 0 & 0 & 0 & 0 & 0 & 0 \\
\hline
\end{tabular}

Table 2: All the numerical values are indicating number of patients.

Duration of study: Follow up was assessed for a period of $1^{\text {st }}$ week, $1^{\text {st }}$ month and $6^{\text {th }}$ month postoperatively and the data was served as a document of patient and was classified in to four different numbers; Normal, Fistula Formation, Deafness and Middle ear problem (Table 3).

\section{Statistical analysis}

Postoperative audiometric findings showed no statistically significant difference ( $p>0.005)$ within both the groups after six months and also when compared to each other, there was no statis- 


\begin{tabular}{|l|c|c|c|c|c|c|}
\hline \multicolumn{1}{|c|}{ Gollow Up } \\
\cline { 2 - 7 } & \multicolumn{3}{|c|}{ Group A } & \multicolumn{3}{c|}{ Group B } \\
\cline { 2 - 7 } & $\mathbf{1}^{\text {st }}$ week & $\mathbf{1}^{\text {st }}$ month & $\begin{array}{c}\mathbf{6}^{\text {th }} \\
\text { month }\end{array}$ & $\begin{array}{c}\mathbf{1}^{\text {st }} \\
\text { week }\end{array}$ & $\begin{array}{c}\mathbf{1}^{\text {st }} \\
\text { month }\end{array}$ & $\begin{array}{c}\mathbf{6}^{\text {th }} \\
\text { month }\end{array}$ \\
\hline Normal & 12 & 12 & 12 & 14 & 14 & 14 \\
\hline $\begin{array}{l}\text { Fistula } \\
\text { formation }\end{array}$ & 2 & 2 & 2 & 0 & 0 & 0 \\
\hline Deafness & 0 & 0 & 0 & 0 & 0 & 0 \\
\hline $\begin{array}{l}\text { Middle Ear } \\
\text { Problems }\end{array}$ & 1 & 1 & 1 & 1 & 1 & 1 \\
\hline
\end{tabular}

Table 3: All the numerical values are indicating number of patients.

tically significant differences ( $p>0.005$ ) in the outcomes between the fracture and non-fracture populations (Table 2). Complication rate in both the groups was statistically not significant ( $p>0.005$ ) (Table 3).

\section{Results}

30 patients were examined in this study with male female predilection of 3:2. In Otoscopic examination (Table 1), $1^{\text {st }}$ and $6^{\text {th }}$ month post-operative findings revealed improvement in both the groups. When both the groups were compared, differences were found in the middle ear status which was improved in both the groups and was statistically significant ( $<<0.005)$. Regarding the findings of Audiometric examinations in both the groups (Table 2), majority of patients had normal hearing impairment preoperatively. 6 months postoperatively audiometric findings (Table 2) showed no statistically significant difference ( $p>0.005$ ) within both the groups and also when compared to each other, there was no statistically significant differences $(p>0.005)$ in the outcomes between the hamulotomy and without hamulotomy populations (Table 2). Complication rate in both the groups was statistically not significant $(p$ $>0.005$ ) (Table 3).

\section{Discussion}

Alt [11] in 1878 confirmed the association between cleft palate and development of otitis media with effusion (OME) if the child with cleft palate had presence of ottorhoea. Still after palatoplasty, there may be a universal consensus that, recovery of Eustachian Tube (ET) function and degree of hearing impairment is a controversy with the occurrence of OME in children with unrepaired cleft palate [12]. In 1889, Billroth [9], was credited for facilitating cleft palate closure after fracturing of pterygoid Hamulus by introduc- ing the movement which requires skill and care. From that day, hamulus fracture was accepted and still now during palatoplasty, it is practiced commonly by the surgeons. But, Millard [13] proposed that Pterygoid hamulus fracture should be avoided as any intervention near the epipharyngeal portion of Eustachian Tube impairs its function. There were many other researchers who had warned against Pterygoid hamulus fracture during palatoplasty. Alternately, some researchers had observed that fracturing of the pterygoid hamulus didn't show any increase in the incidence of deafness [14] sand no changes in middle ear pressure [15], while other researchers found that post hamulotomy there is threefold increase in middle ear effusion [16]. Thinking about all these different schools of thought and gap in the research regarding effects of hamulotomy or, non-hamulotomy; we performed cleft palatal repair surgery with and without hamulotomy on randomly basis to compare and evaluate its effect on middle ear and hearing ability postoperatively. There is a lack of uniformity in the age group of the present study subject and age stratified data. Beside everything, there is a dissimilarity in the ethical issues relating to various examination methods for a specific age group. So, to overcome all these problems, a specific age group of pre-school age children (aged below 5 years) was selected for this study. After evaluating and studying the scenario of the age of the patients, it was quite impossible to acquire the co-operation or, to examine them. By use of Valsalva maneuver, it was inappropriate in this age group due to lack of co-operation from them. So, otoscopic examination was used for investigate the tympanic membrane appearance and mobility. Moreover, it was impregnable to go the route of subjective hearing assessment test like pure tone audiometry in subjects of this age group [17]. However, child's auditory status can be obtained by bringing objective hearing tests into play. Tympanometry is the best clinical exam to detect of presence or absence of OME for objective test. The Brainstem Evoked Response Audiometry (BERA) is an another objective test which is an electro physiological assessment method that measures the electrical activity of the auditory system. BERA approaches as a reference standard and was ideally a reliable test for interpretation of hearing impairment as stated by previous researchers [18]. There are only three comparative studies which seeks to rule out the effects of hamulotomy on middle ear pathology in cleft palate population which is similar to the present study. Noone., et al. [19] studied the prospective evaluation of the effects followed by hamulotomy during palatal repair surgery on middle ear disease and he randomized the patients for unilateral hamulotomy. And, in another prospective study which was conducted by Kane., et al. [9] hamulotomy was achieved 
on an alternate basis and the outcome of hamulotomy was studied postoperatively. Both these prospective and, comparative studies showed no any statistically significant difference in postoperative incidence of OME and hearing impairment. After all of these prospective studies, a single retrospective study was done by Sheahan., et al. [20] where they compared the results and questioned about it and found that there wasn't any significant difference. They also concluded that there was no proof of hamulotomy which affected long-term otological outcome in cleft palate. They also stated that "hamulotomy avoidance during palatal repair surgery may result in less alteration of Eustachian Tube function and may thus be an simplism of a complex problem".

Our study exhibited; no statistically significant difference for audiometric examination ( $p>0.005$ ) but statistically significant difference for otoscopic examination $(p<0.005)$ when compared both the groups, which signifies no postoperative alteration in Eustachian Tube function and subsequent reduction of Otitis media with effusion. Erroneous insertion of velar musculature detaches from the bony margins of cleft palate due to which the muscles functions and the postoperative improvement may be seen. Hamulomy or, without hamulotomy does not give any picture of postoperative fistula. So, in wider clefts, successful closure can be done without hamulotomy and for repairing of narrow or, moderate clefts hamulotomy may not require.

These findings are in accordance with the work of the abovementioned researchers.

\section{Conclusion}

This present prospective clinical study concludes that with hamulotomy or, without hamulotomy do not affects or, changes the hearing and function in cleft palate community which is included in this study for a follow up of 6 months period. Also, statistically significant difference was null in the same 6 months follow up period; so for narrow, moderate or, wider clefts efficient closure can be done without hamulotomy.

\section{Conflict of Interests}

The study was conducted in SGT University and the treatment was free of cost excluding medicine charges. There is no conflict of interests regarding the publication of this paper.

\section{Bibliography}

1. Philip S and Gudrun E. "Genetics of cleft lip and palate: syndromic genes contribute to the incidence of non-syndromic clefts". Human Molecular Genetics 13.1 (2004): 73-81.
2. Fonseca J. "Cleft Craniofacial Cosmetic Surgery". Company Saunders B W 6: 3.

3. Hassan M and Askar S. "Does palatal muscle reconstruction affect the functional outcome of cleft palate surgery?" Plastic and Reconstructive Surgery 119.6 (2007): 1859-1865.

4. Karoon A. "Cleft palate repair and variations". Indian Journal of Plastic Surgery 42.10 (2009): 102-109.

5. Mahmoud F Elbestar and Mamdouh A. "Furlow Palatoplasty: A Preliminary Study". Egyptian Journal of Plastic and Reconstructive Surgery 29.1 (2005): 55-59.

6. Venkatesh R. "Syndromes and anomalies associated with cleft". Indian Journal of Plastic Surgery 42.10 (2009): 51-55.

7. Barchetta N., et al. "Clinical and morphofunctional aspects of pterygoid hamulus: literature review". Bachelor of Dental Surgery 18.4 (2015): 5.

8. Putz R and Kroyer A. "Functional morphology of the pterygoid hamulus". Annals of Anatomy 181.1 (1999): 85-88.

9. Kane A., et al. "The Effect of Hamulus Fracture on the Outcome of Palatoplasty: A Preliminary Report of a Prospective, Alternating Study". The Cleft Palate-Craniofacial Journal 37.5 (2000): 506-511.

10. Ani H., et al. "Cleft Palate Repair without Fracture of the Pterygoid Hamulus". The Iraqi Postgraduate Medical Journal's 5.3 (2006).

11. Dhillon R. "The middle ear in cleft palate children, pre and post palatal closure". Journal of the Royal Society of Medicine 81.12 (1988): 710-713.

12. Paradise J., et al. "The universality of otitis media in 50 infants with cleft palate". Paeditrics 44.1 (1969): 35-42.

13. Millard D. "Alveolar and Palatal Deformities, of Cleft Craft: The Evolution of its Surgery". Little, Brown and Comp (1980): 3.

14. Chaudhuri P and BowenJones E. "An otorhinological study of children with cleft palates". The Journal of Laryngology and Otology: JLO 92.1 (1978): 29-40.

15. Holborow C. "Deafness associated with cleft palate". The Journal of Laryngology and Otology: JLO 76.10 (1962): 762-767.

16. Odoi H., et al. "Effects of pterygoid hamulotomy upon Eustachian tube function". The Laryng 81.8 (1971): 1242-1244. 
17. Zingade N and Sanji R. "The prevelence of otological manifestations in children with cleft palate". Indian Journal of Otolaryngology and Head and Neck Surgery 61 (2009): 218-222.

18. Yang F., et al. "Evaluation of an auditor assessment protocol for Chinese infants with nonsyndromic cleft lip and/or palate". The Cleft Palate-Craniofacial Journal 49.5 (2012): 566-573.

19. Noone R., et al. "The effect on middle ear disease of fracture of the pterygoid hamulus during palatoplasty". The Cleft PalateCraniofacial Journal 10 (1973): 23-33.

20. Shehan P. "Long-term otological outcome of hamular fracture during palatoplasty". Otolaryngology-Head and Neck Surgery 131.4 (2004): 445-451.

\section{Assets from publication with us}

- Prompt Acknowledgement after receiving the article

- Thorough Double blinded peer review

- Rapid Publication

- Issue of Publication Certificate

- High visibility of your Published work

Website: www.actascientific.com/

Submit Article: www.actascientific.com/submission.php

Email us: editor@actascientific.com

Contact us: +919182824667 